\title{
CURRENT AND POSTWAR PROBLEMS ASSOCIATED WITH THE HUMAN PROTOZOAN DISEASES
}

\author{
By L. T. Coggeshall \\ University of Michigan, Ann Arbor, Michigan
}

INTRODUCTION

The present war is providing unparalleled opportunities for the entrance into this country of pathogenic agents and disease vectors that have played little or no part in our past medical history. Chief among the diseases most likely to exert their influence over us is the protozoan group and their near relatives which thrive in tropical and subtropical areas because of favorable climatic conditions and lack of adequate control. In the past, some have had their distribution limited to fairly restricted areas, largely because of climatic and physical barriers which affect host and parasite alike. However, the majority have a very widespread distribution and would seem to need only slight aid to extend their boundaries into unaffected but receptive territory. A major portion of our troops on foreign soil is now in highly disease-ridden areas. In some places they are acquiring infections from the native reservoirs at an alarming rate. By the rehabilitation of sick troops these recently contracted diseases are being transposed to the United States in large numbers. Whether the infections succeed in establishing themselves in their new environment is yet to be learned but we cannot assume that they will disappear spontaneously because our soil is unfriendly. Therefore it must be agreed that all are potentially dangerous and unless energetic measures are instituted to curb their activity we may face serious consequences. In this discussion I should like to present evidence for considering these foreign diseases and their vectors as immediate hazards to present and future health.

\section{BIOLOGICAL BEHAVIOR OF PROTOZOAN DISEASES}

To understand why the Protozoa in particular and their relatives, the filariae and schistosomes, are of special importance one needs only to review their biological characteristics. If I were asked what features distinguish them as a group I would reply that in general it would be their tendency to produce chronic infections and their inability to leave more than a transitory immunity in their respective hosts. With the excep- 
tion of the amoebae and the intestinal flagellates, the pathogenic agents under discussion have complicated life histories in man and their intermediate insect hosts. The malarial plasmodia, trypanosomes, leishmaniae, filariae, and schistosomes possess strict requirements for survival which would seem to make them liable for extinction. On the other hand, they have compensated for this handicap by their capacity to exist almost indefinitely in man. It is to their advantage not to destroy their host but to establish a permanent host-parasite relationship. For example, both the amoebae and the intestinal flagellates persist almost indefinitely in the intestinal tract of man. The malarial plasmodia go through no less than twelve distinct morphological stages in man and mosquito. In the latter the infection lasts only a few weeks but in the human host it runs a very chronic course with a tendency to relapse repeatedly. Actually there are cases on record where malarial infections have lasted a score or more years. For example, there was a Greek in Denver who remembered having had a malarial infection in Greece shortly before he became an immigrant to this country at the age of ten. After residing 37 years in Denver, where malarial transmission does not occur, he gave his blood for transfusion purposes and the recipient came down with quartan malaria. Upon examination of the donor's blood circulating parasites were found, yet he had never had any symptoms referable to the disease in the interim between the initial infection and the transfusion episode. There are many other similarly authenticated reports, usually involving the quartan parasite, the most chronic of the malarial infections. Vivax and falciparum malaria are of shorter duration, but they do not die out when the acute infection subsides. Any one of the returning infected soldiers, the majority of whom will have the dreaded falciparum malaria because they are largely in areas where that species is predominant, conceivably can serve as a focus for many months or even years. The vector for malaria in the United States, Anopheles quadrimaculatus, is abundant as far north as the Canadian border. It is capable of transmitting all of the human plasmodia and will not need to depend upon a single exposure to become infected, but will have repeated opportunities to feed upon chronic or relapsing cases.

Trypanosomiasis is one of the dreaded tropical diseases and thus far has been confined largely to the tropics. The African form, sleeping sickness, is limited to the distribution of its vectors, the Glossina or tsetse flies. Both the African and Western Hemisphere varieties produce long-standing infections. In the former the terminal stages usually are not reached until the third year. In the latter, Chagas, for whom the disease was named, believed that if an individual did not die in the 
initial attack he would develop a chronic infection that would last indefinitely.

Leishmaniasis, both the visceral and cutaneous variety, known as kala azar and oriental sore respectively, is a chronic infection. Its duration is especially prolonged. A variety of oriental sore, known as espundia, is present in parts of the Western Hemisphere, and has the same chronic characteristic.

The filarial organism, Wuchereria bancrofti, that causes elephantiasis, rarely subsides of its own accord but establishes a relationship with the human host that persists for many years. Death intervenes only when secondary infections occur.

Schistosomiasis, so prevalent in Africa, the Middle and Far East, and South America, is another example of a very chronic disease. Any infected individual is capable of releasing thousands of. ova from the intestinal or urinary tract for years.

Thus we can readily see that this group of diseases possesses as one of its special behaviors the tendency to produce infections of long duration. Whether in their evolutionary development it has been necessary for them to acquire this characteristic in order to survive is not known. However, if introduced into new areas we do know by this same feature that they can serve as sources of infection over long periods and thus enhance their chances for spreading.

The nature of the immunological reactions produced in man as the result of infection with the above mentioned diseases furnishes some information on the probability of their danger to us. As a group they probably induce no more than a transitory immunity. For example, when amoebic infections disappear spontaneously or are cured by specific therapy there is no residual immunity and there can be subsequent attacks as severe as the initial one. The same is true of malarial infections as they confer no lasting immunity upon their hosts after complete recovery. An attack of any one of the three human plasmodia offers no protection against the other two. As a matter of fact there is no cross immunity between strains of the organism within the same species. James ${ }^{1}$ was the first to show that after the acute attack of malaria had subsided the individual was highly immune to the homologous strain of vivax malaria, yet as susceptible as any normal when inoculated with the same species imported from a distant area. Less is known about the immune responses to the human trypanosomes or leishmaniae but there is little or no evidence of a permanent efficient

\footnotetext{
1 Jamos, 8. P. Some general results of a study of induced malaria in England. Trang. Roy. Soc. Trop. Med. and Hyg. 24: 477. 1091 .
} 
immunity response and it is possible to produce experimentally repeated attacks in some of the lower animal hosts. It seems significant that as yet there are no effective vaccines for any of the protozoan infections. If one is permitted to make a generalization on this point it would be that diseases associated with the minimum duration of immunity offer the least hope for artificial immunization. If this group of diseases conferred permanent immunity after the initial attack then their hosts would not serve as an indefinite source of danger.

\section{ACQUISITION OF INFECTION IN TROPICAL AREAS}

Another important factor is the acquisition of the various infections in tropical zones. As a country without colonies we have had relatively few contacts with the tropical world, with the exception of Panama, the Philippines and a few Caribbean Islands. Even a considerable proportion of our maritime commerce has been conducted by foreign crews and ships. With the advent of the war it suddenly became necessary for us to transport huge numbers of troops overseas and a major part of them is ncw in tropical areas. For the most part they are in places that enjoy the dubious reputation of being the foremost disease centers of the world-Africa, the Middle East, India, China and the Southwest Pacific. If we ever approach the proposed figure of $11,000,000$ men in the armed services, approximately one-half of our male adult population, and if the same proportions are to serve in the tropics as now, then we can gain some appreciation of the probable consequences, if only a small percentage acquires one or more of the tropical infections. We need not speculate on the probability of these troops becoming infected, because it is already a fact.

Malaria and dysentery are and will undoubtedly continue to be the chief offenders. In the latter group the amoebae are important because of their prevalence and widespread distribution. Amoebae occur endemically throughout all the tropical countries and in most areas cause the prevailing form of dysentery. The incidence of infection found by survey in various native populations usually varies between 10 and 25 per cent. On the Gold Coast in West Africa it was found by routine monthly stool examinations that approximately 12 per cent of the native Africans employed as food handlers along an American air route were infected with Endamoeba histolytica. This percentage was increased to 20 when purgation was used to obtain liquid stools. In approximately 1000 airline personnel, only 16 acute cases developed during a year's operation. Surveys throughout the United States show that 5 to 10 per cent are carriers of $E$. histolytica, so the dangers of intro- 
ducing new strains should not cause much apprehension unless they are much more virulent. On the other hand possibilities of serious outbreaks are not remote as witnessed by the severe Chicago epidemic which embraced at least 1400 severe cases and 52 deaths.

Malaria is the predominant disease in the tropics. In Liberia, for example, repeated surveys were made among the natives in villages adjacent to our troops. The average number of children showing circulating parasites was near 100 per cent, while in adults the figure averaged 70 per cent. These rates are high but not excessive for Africa. Our troops are highly susceptible to this infection. In my own experience with the personnel of a large airline, during one month over 40 per cent were incapacitated within eight weeks of their arrival in a West African country. ${ }^{2}$ In combat areas where control is very difficult, malaria reaches epidemic proportions. At the fall of Bataan it was estimated that 85 per cent of each regiment had acute malaria. In some areas of the Southwest Pacific the incidence is almost as high. Recent arrivals of United States troops from these areas show that a high percentage of the medical cases are suffering from malaria or have recently recovered from its effects.

Leishmaniasis is not just a term for an exotic disease that occurs sporadically. Its incidence is very high especially in Africa and the Middle and Far East. An average of 60,000 cases are treated annually in Assam province. This represents only a fraction of the actual number of cases. In 1937, in Bengal, 137,000 individuals presented themselves for treatment. In Africa the chief centers are in Morocco, Algeria, Tunisia, Tripolitania, and Egypt. These names are significant to all of you. Recently the disease has been reported in the Western Hemisphere especially in South America.

Trypanosomiasis occurs in the proximity of our troops in several parts of Africa. Although it is not so prevalent as the other protozoan diseases, there is an appreciable number of cases. For example, in Liberia the rates are about one in 500 in the coastal natives. White persons are susceptible, but less so than the negroes, apparently because of the preferential biting habits and opportunities for bites of the tsetse fly.

Schistosomiasis, although not a protozoan infection, presents similar problems and should be mentioned. It has a widespread distribution in the Mediterranean countries, Middle and South Africa, and the Near and Far East. During the early slave-trading days, schisto-

\footnotetext{
2 Cogrenhall, I. T., ot al. Experiences in the development of a medical service for alrline operations in Africa.' War Medicine. 8: 484; 619. 1948.
} 
somiasis was introduced into South America and Scott ${ }^{3}$ reported in 1940 that Schistosoma mansoni was as prevalent and severe in some parts of Venezuela as any place in the world. In the males above 10 years the incidence of infection is about 90 per cent. This infection is readily acquired by contact with larvae in infected waters, and the Caucasian race is extremely susceptible. The British have a rule that if any soldier falls into fresh water in infected areas he must go immediately to a place where a disinfecting bath can be taken. The widespread migrations through areas where schistosomiasis is prevalent can result in some infections. Craig and Faust ${ }^{4}$ speak of two cases after the last war of $S$. haematobium acquired in Australia from water contaminated by soldiers returned from the Middle East. Fortunately no outbreak occurred. Two cases of $S$. haematobium were also reported from Michigan by Blum and Lilga ${ }^{5}$ in December, 1942, in boys who were originally infected in Africa. One of the cases was particularly interesting because the diagnosis was first made on a routine urine examination in April. But from the history it was certain that the boy became infected four months previously. In spite of the best quarantine precautions it is likely that this infection would have been missed when he entered the country in February. The schistosomiasis of the Old World has a close relationship with a schistosome dermatitis, commonly called "swimmer's itch," that occurs in the northern region of this country. The latter variety is relatively non-pathogenic for man, as it produces only a local reaction when the larvae penetrate and die in the skin. It is not known, however, that the more dreaded $S$. mansoni, haematobium or japonicum will not find snails here receptive to their development upon chance introduction. We know therefore that there are sufficient opportunities for our men to contract the various protozoan infections, especially malaria and dysentery which are already responsible for adding a large number of names to the casualty lists.

\section{DISSEMINATION OF DISEASE BY MODERN TRANSPORTATION}

Another epidemiological factor now confronting us for the first time is the speed of modern transportation, particularly by air. Not only is there an increase in speed but also in the amount of air traffic. It may be stated that this type of transportation has been going on for several years even through the heavily infected tropical belts. But there is a

'Bcott, J. A. Schistosomiasis in irrigated mountain valleys of Venezuela. Am. Jour. Hyz., Sect. D. 31: 1. 1940 .

Craig, C. F., \& Faust, 15. O. Clinical parasitology, p. 871. 1940.

- Blum, B. B., L Lige, $\vec{H}$. $\vec{\nabla}$. Schistosomianis infection: report of two cases found in northern Michigan. Jour. Am. Med. Asan. 181: 125. 1948. 
difference now. Before the war, traffic was confined mostly to passengers of the higher income brackets who stopped at the better sanitated hotels in the larger cities and had a minimal contact with native population. Now most of the air travelers are individuals who have lived in close proximity with the infected natives, many for long periods. Actually air transport will be the means of returning large numbers of sick personnel, as it was announced in the press recently that air evacuation units are now in operation carrying 22 patients in each plane from Africa to the United States. Speed of travel is an important factor because it permits the entrance of infected individuals into new areas before the incubation period has elapsed. For example, in my own experience I recently arrived in the United States 34 hours after departing from Africa. It would have been possible to have contracted any of the infections previously cited shortly before leaving and yet have had several days of apparent good health in this country before diagnostic symptoms developed.

The task of excluding diseases and their vectors by the United States Public Health Service at regular ports of entry during normal times has been extremely difficult. Under disturbed conditions when large numbers of transoceanic planes are arriving, frequently unannounced and on irregular schedules at any one of scores of airports, the quarantine duties are multiplied enormously. With the exception of the route to the British Isles practically all of the foreign air traffic to the United States originates in the tropics-in the Southwest Pacific, South and Central America, the Caribbean area, Middle and North Africa, the Middle East, Russia, India and southern China. The airports in these places are usually located in the insanitated areas frequently hacked out of the jungle and surrounded by native villages whose occupants are being used as laborers. Every incoming flight presents a real hazard.

There is danger of transporting not only the diseases themselves but also their vectors. We have had a real lesson in what can happen from the accidental introduction of Anopheles gambiae into South America about 1930. This insect multjplied at a prodigious rate and the first six months of 1938 witnessed a malarial epidemic involving a minimum of 14,000 deaths and 100,000 cases. The eradication of this species of mosquito from Brazil by the joint efforts of the Brazilian government and the Rockefeller Foundation will go down in history as one of the outstanding achievements in preventive medicine. ${ }^{6}$ The results of this campaign illustrate the necessity of applying energetic control methods. Neglect could have resulted in disaster for all of the tropical areas of the

\footnotetext{
- Boper, T. I., wlleon, D. B. Species eradication. Jour. Nat. Malaria Soc. 1: 6. 1948.
} 
Western Hemisphere. Incidentally, within the past year the same mosquito has been found on a few occasions in planes coming from Africa. Also one tsetse fly was found. Fortunately all insects were dead as the result of disinfestation of the planes with insecticides at their points of departure and arrival.

Insect vectors will be covered later in the symposium but their importance cannot be overemphasized. The volume of air transportation now being carried on is affording daily opportunities for bringing these vectors of disease into our country. Unless destroyed by spraying they will probably arrive in a healthy condition because of the brief time required for the journey. Finally, if they are able to establish themselves it is very probable they will multiply more rapidly than in their natural habitats. It is a fundamental law of nature that when any biological species is transported to a new favorable environment it multiplies very rapidly because it has left its natural enemies behind. Such examples are the Japanese beetle in the United States and Anopheles gambiae in Brazil.

A factor of major health importance in all wars is the development of epidemics among disturbed populations. Epidemics do occur in times of peace but they are usually confined to relatively limited areas because the topography or climate seems to check their spread. Last year I saw several thousand Poles coming out of Russia into Persia who had been uprooted from their homes and many of whom were ill. Many had virulent malaria acquired around the shores of the Caspian Sea. Several varieties of dysentery were evident in large numbers and cases of typhoid were extremely numerous. Typhus had just disappeared, as it was the onset of the hot season. In spite of aid they were receiving from the American Red Cross and the British they were living in a very makeshift fashion and they were contracting and spreading many diseases. There would be minimum danger except to themselves if they were to remain in this area, as there would be only an increase in the reservoir of the disease already present. The real danger will come as the result of their mass migration, as they soon will be dispersed into East Africa, India and other places. A migratory people can initiate epidemics in tropical areas even if the responsible disease is already prevalent. For example, it is a common occurrence for malaria to break out in troops when they are moved to other infected areas, even if they have previously acquired considerable tolerance to the disease. The explanation usually given is a lowered resistance due to fatigue, improper food, etc. A more likely reason is that they have come in contact with a strain of the disease with which they have had no previous experience. At the same 
time they may carry with them a strain which will adversely affect the people who are permanent residents of the area. During the past war malaria returned home with the infected soldiers and secondary epidemics developed in several parts of England. At Emden, on the north coast of Germany, there were 6000 cases. The worst epidemic of all occurred in Russia where the starving civilians came down with malaria by the thousands. The Red Cross reported $3,000,000$ cases in the Republic west of the Urals, in Georgia one-half of the population was affected, and in villages near Tiflis two-thirds of the population died of malaria. Malaria was present in all of these areas yet the probable introduction of new strains coupled with factors conducive to rapid transmission resulted in severe epidemics. The mass migration of returning soldiers can induce comparable consequences in this country.

\section{SUMMARY}

Summarizing the factors that are aiding the protozoan group of diseases and some of their near relatives in obtaining new footholds, we find the most important to be the massive concentration of susceptible troops in some of the foremost disease centers of the earth. It has already been found that these men are acquiring infections, particularly malaria and dysentery, in alarming proportions. Time alone will tell whether the other pathogenic agents can gain access to these fresh hosts and there is no reason to assume this will not happen as every opportunity is present. The rehabilitation of the sjck will disseminate the acquired infections to every part of our country and it seems quite likely that there will be some favorable places that will serve as the foci for epidemics. We must be alert in recognizing the imported diseases in all of their stages so that they can be treated, isolated or otherwise controlled in order to minimize their danger to us. For the postwar period we will not only be concerned with the effects of tropical diseases on our own soil but will take a leading role in preventive medicine throughout the world. Training centers must be provided for increased teaching facilities and opportunities for fundamental research so that we can more ably fulfill the responsibilities that will come to us as the result of our greater contacts with these less familiar diseases.

Although in many respects the immediate prospects seem fraught with danger, I believe that the long-term picture is one of extreme opportunity of service for all mankind. Finally in this reorganized world that will surely follow the war, we cannot continue to follow the British, Dutch, Russians, Germans or any other nation in the study of tropical diseases but must assume a comparable role, if not a leading one. 


\section{DISCUSSION OF THE PAPER}

Dr. W. H. Wright (United States Public Health Service, Washington, D. C.):

I am here in the difficult role of substituting for Dr. Thomas Parran, Surgeon General of the United States Public Health Service, who wishes me to express his regrets at his inability to be present at this Conference.

As the Federal agency most concerned with civilian health, the Public Health Service is not only interested in endemic disease but for 150 years has maintained a watchful eye lest the flotsam of some epidemic in some far-off corner of the globe be cast on our own shores. Now that we are engaged in a global war, the possibilities of the introduction and establishment of exotic diseases have been increased enormously. Consequently, the Public Health Service is vitally interested at this time in many diseases, protozoal and otherwise, which may become of domestic importance, or whose domestic distribution may be enhanced as a result of our military endeavors. Let us review briefly some of the present and postwar problems as they concern the public health significance of certain protozoal diseases.

Our malaria problem in World War I was confined to the southern camps and extra-cantonment areas. For the most part our troops were engaged in temperate or cold climates where malaria was not endemic. But now the sons of the veterans of the Marne and the Meuse, Archangel and Siberia, are in combat in some of the most highly malarious areas on the globe. Many of these men will return as carriers of the disease and many will go back to their homes in parts of the country which have long been free of the disease. A proper concentration of carriers in areas where there is a suitable concentration of vectors will lead to the establishment of new endemic centers of malaria. Furthermore, there is the possibility, if not the likelihood, of the introduction of new strains or new species in areas in which all the several species do not exist at present. We already have isolated examples of the potentialities of such occurrences even with the introduction of a limited number of carriers. For instance, Craig has cited the incident of the National Guard company from Connecticut, the members of which contracted Plasmodium falciparum infection in southern camps during the Spanish-American War and introduced this species in their home community on their return from the service, a community in which only $P$. vivax had previously been known. Matheson has cited the Aurora, Ohio, outbreak of 1934 to show the explosive effect of the introduction of a single case in a community, in which a suitable mosquito host was available. We may anticipate as a postwar development the probable occurrence of numerous instances of this sort.

On the other hand, our participation in the war will not be entirely on the debit side so far as malaria is concerned. Certain advantages will accrue to us. We must place on the credit side the gains we are making in the control of malaria in extracantonment areas in the South, our capacity to produce large quantities of synthetic antimalarial drugs, our research which should produce additional facts concerning the epidemiology of the disease, the ecology of vectors, and drug control, and last but not least the increased knowledge of malaria and other tropical diseases on the part of our physicians serving with the armed forces.

\section{AMOEBIASIS}

With amoebic dysentery also, we are faced with a situation somewhat different than we were in the first World War. Not so long ago, an eminent medical officer remarked to me that amoebic dysentery has never been a military problem except in the Philippines during the Spanish-American War and the Insurrection. His statement is entirely true but at the same time we must not forget that the Philippine campaign is the only one of consequence which we had fought in a tropical country. Now our troops are in combat in areas in which strains of Endamoeba histolytica are particularly virulent, not for the indigenes, but for susceptible individuals who have not developed resistance through previous and perhaps long-continued exposure.

The protection of troops against bacillary and amoebic dysentery is difficult under combat conditions. Superchlorination of water will destroy cysts of $E$. histolytica and portable filters such as used in advance zones will probably remove such cysts from water. However, even though the best sort of protection is provided, it 
is not always possible under combat conditions to make use of available facilities. Consequently, the dysenteries must be reckoned with in any military campaign.

It is difficult to appraise the effect of the dispersal of numerous returning carriers of $E$. histolytica throughout our civilian population. The question was raised during the last war and Boeck and Stiles made a total of 13,043 examinations of 8029 individuals for intestinal parasites. These persons included overseas veterans, troops stationed in the United States, persons with no military service, and persons whose service connection was unknown. The incidence of $E$. histolytica in overseas soldiers was no higher than that encountered in the other groups. Conditions for our military operations are now entirely different and we may expect the return of a larger number of infected individuals at the end of this war. What effect these carriers will have on our civilian health is problematical but it is reasonable to assume that their dispersal may well lead to a higher morbidity rate from amoebiasis, and that perhaps new and more virulent strains may be introduced.

In the meantime, all our problems in amoebiasis are not postwar problems. Bome have been with us for a long time. For instance, we are weak in our knowledge of the varying virulence of strains and of the factors influencing susceptibility to the disease; we need more potent and more specific antigens for serological and intradermal tests so that diagnosis can be simplified; we should have greater knowledge of the epidemiology of the disease and the relative importance of different modes of transmission; and our chemotherapeutic methods could stand a lot of improvement.

\section{LEISHMANIASIS}

Other than a few imported cases, leishmaniasis has not occurred in the United States. Even though the method of transmission of the visceral type of the disease has been definitely established by Swaminath, Shortt and Anderson, as occurring through the bite of Phlebotomus, we have difficulty in appraising postwar significance of the disease as a public health problem in the United States. We do know that protection against the vector is often impractical, if not impossible, and that in the present state of our knowledge only the most obvious cases are detected by routine diapnostic procedures. We may surmise therefore that individuals with the disease will return to the United States. I believe that only three species of Phlebotomus are known from the United States, two of them imperfectly. One species, $P$. diabolicus, occurring in Texas, is known to be a decided feeder on man. It is believed that studies should be conducted to determine the distribution and ecology of the indigenous species of Phlebotomus and that experiments are in order to determine whether $P$. diabolicus can serve as a vector of leishmaniasis.

\section{TRYPANOSOMIASIS}

The possibilities for the establishment of African sleeping sickness in this country are perhaps more remote than those in the case of some other exotic diseases. Of course, we do not have in this country species of Glossina, a fact which mitigates against the establishment of the disease in the continental United States. However, we do have other blood sucking flies including tabanids and Stomoxys calcitrans, the latter of which has been incriminated as one of the vectors of the disease. As African trypanosomiasis has exhibited no tendency to spread extensively in areas where Glossina does not abound, it would appear that the disease is unlikely to gain a foothold in areas where dependence on transmission is limited to other vectors.

Perhaps we should be more concerned over the possible establishment of Chagas' disease than of the African variety of trypanosomiasis. It is a well-known fact that naturally infected Triatoma have been found in several places in the South, Southwest, and California, and that reservoir hosts of Trypanosoma cruzi are present in this country. No human cases of the disease have apparently been found to date. However, we are sending on different missions many individuals to endemic areas in Central and South America and furthermore we are importing Mexican labor to work in areas in which infected Triatoma have been found. We can only conjecture the effect of these various circumstances and hope that they will not be sufficiently fortuitous to bring about the introduction of human cases and the spread of the disease in this country.

One cannot leave this question without saying a brief word concerning the vigi- 
lance necessary to prevent the introduction of disease vectors into this country. The reverberations which followed the introduction of Anopheles gambiae into Brazil are still sufficiently audible that no further example is needed to stress the importance of this sort of thing. The enormous expansion of air travel within the past year and the addition of transport routes to all corners of the globe have brought about a constant and increasing peril in this respect. The Public Health Service is alert to all of the potential possibilities in the situation and is exerting every effort to guard our shores against the introduction of disease-transmitting species. The adoption of aerosol spraying for airplanes has added to the efficiency of plane fumigation and we may expect the continued adoption of new plans and new methods as the need asserts itself.

Dr. Robert Matheson (Cornell University, Ithaca, N. Y.):

Some of my observations also illustrate the fact that malaria will remain in the blood stream for many years without necessarily causing symptoms. For instance, there is a record of a six-year-old child in Ithaca, N. Y., who developed a severe case of malaria (Plasmodium falciparum) within 48 hours of receiving a transfusion from her father, a Syrian, who had lived in the United States for 35 years without noticeable symptoms. 